\title{
MODEL KECEPATAN 1-D GELOMBANG P DAN GELOMBANG S DARI DATA HASIL RELOKASI HIPOSENTER DI WILAYAH GUNUNG SINABUNG
}

\author{
Abraham Arimuko*, Yoga Dharma Persada, Hendri Subakti \\ Prodi Geofisika,Sekolah Tinggi Meteorologi Klimatologi dan Geofisika' Tanggerang Selatan \\ Email : abrahamarimuko98@gmail.com
}

\begin{abstract}
ABSTRAK
Gunung Sinabung merupakan gunung yang aktif kembali setelah tidak beraktifitas (dorman) selama lebih dari 400 tahun. Gunung Sinabung sampai saat ini melakukan aktivitas vulkanik. Hal itu membuat masyarakat di sekitar lereng Gunung Sinabung berwaspada. Salah satu aktivitas vulakanik tersebut adalah gempa vulkanik. Penelitian ini bertujuan merelokasi hiposenter untuk mendapatkan model kecepatan 1-D gelombang $P$ dan gelombang $S$ di Gunung Sinabung yang dapat digunakan sebagai data acuan kondisi bawah permukaan. Penelitian ini menggunakan input data magnitudo, parameter hiposenter, serta waktu jalar gelombang $P$ dan gelombang S. Data ini diperoleh dari BMKG EQ (Earthquakes) Repository. Kejadian gempa bumi yang digunakan pada rentang waktu 1 Januari 2017 sampai 28 Februari 2017 dan pada koordinat 3,0931 LU3,3543 ${ }^{\varpi U}$ dan 98,2928 BT-98,6202 BT. Pada pengolahan ini juga menggunakan parameter letak stasiun (sensor). Data tersebut direlokasi menggunakan software VELEST 3.3 dengan model kecepatan global IASP91 sebagai model kecepatan awal. Hasil dari relokasi tersebut adalah koreksi letak stasiun (sensor), parameter hiposenter akhir, waktu jalar gelombang seismik, dan model kecepatan 1-D gelombang $P$ dan gelombang $S$. Hasil yang didapatkan untuk model kecepatan 1-D gelombang P pada kedalaman $0 \mathrm{~km}$ sebesar $5.58 \mathrm{~km} / \mathrm{s}$ dan untuk kedalaman $210 \mathrm{~km}$, lapisan terdalam pada pengolahan data ini, sebesar $8.30 \mathrm{~km} / \mathrm{s}$.
\end{abstract}

Kata kunci : relokasi, Joint Hypocenter Determination, model kecepatan lokal, Gunung Sinabung

\begin{abstract}
Mount Sinabung is an active volcano after no activity (dormant) for more than 400 years. Mount Sinabung to this day performs volcanic activity. It makes people around the Mount Sinabung's slopes are worried. This research purposed to relocate hypocenter to get model of speed of 1-D wave P and $S$ wave at Mount Sinabung which can be used as reference data of subsurface condition. This study uses the input data magnitude, hypocenter parameters, and the arrival time of $P$ wave and $S$ wave. This data is obtained from $B M K G E Q$ (Earthquakes) Repository. The occurrence of earthquakes used in the time span from 1 January 2017 to 28 February 2017 and at coordinates of 3,0931 ${ }^{\circ} \mathrm{N}-3,3543^{\circ} \mathrm{N}$ and $98.2928^{\circ} \mathrm{E}-98.6202^{\circ} \mathrm{E}$. In this processing also uses the parameter location of the station (sensor). The data is relocated using VELEST 3.3 software with IASP9I's global speed model as the initial speed model. The result of the relocation is the correction of the station position (sensor), the final hypocenter parameters, the seismic wave timing, and the 1-D wave model $P$ and $S$ waves. The results obtained for the 1-D wave velocity model $P$ at a depth of $0 \mathrm{~km}$ is $5.58 \mathrm{~km} / \mathrm{s}$ and for a depth of $210 \mathrm{~km}$, the deepest layer in this data processing, amounted to $8.30 \mathrm{~km} / \mathrm{s}$.
\end{abstract}

Keywords : relocation, Joint Hypocenter Determination, local velocity model, Mount Sinabung 


\section{PENDAHULUAN}

Gunung Sinabung merupakan gunung yang aktif kembali setelah tidak beraktivitas (dorman) selama lebih dari 400 tahun. Gunung Sinabung mengeluarkan material debu, gas, dan mineral seperti karbon dioksida, karbon monoksida, sulfur, nitrogen, serta mineral lainnya sejak 2010 jika aktivitas vulkanik meningkat. Menurut Kepala Pusat Vulkanologi dan Mitigasi Bencana Geologi (PVMBG), Badan Geologi Kementerian ESDM Hendrasto, pada awalnya Gunung Sinabung adalah Gunung Api strato tipe B atau sejarah letusannya tidak tercatat meletus sejak tahun 1600-an. Namun untuk pertama kali setelah lebih dari 400 tahun tidak ada aktivitasnya, kemudian terjadi letusan freatik pada 27 Agustus 2010. Letusan Gunung Sinabung pada 27 Agustus 2010 dikategorikan tipe letusan freatik yang diikuti jatuhan abu vulkanik yang menyebar ke timur-tenggara Gunung Sinabung dan menutupi Desa Sukameriah, Gungpitu, Sigarang-garang, Sukadebi, dan Susuk. Sejak saat itu Gunung diklarifikasikan tipe A. (Sumber: https://www.merdeka.com, 1/3/18). Pada tahun 2014, letusan Gunung Sinabung menewaskan 16 warga dan pada Mei 2016, erupsi material panas menewaskan 7 orang. (Sumber: http://www.dw.com, 1/3/18). Gunung Sinabung kembali meletus pada tanggal 19 Februari 2018 pukul 08.53 WIB namun tidak terdapat korban jiwa. Aktivitas Gunung Sinabung perlu dikaji lebih lanjut agar tersedia data yang digunakan untuk menganalisa pola aktivitas dan kondisi bawah permukaan. Hasil dari analisa data dapat dimanfaatkan untuk pengambilan keputusan mitigasi ketika aktivitas Gunung Sinabung meningkat.

Aktivitas vulkanik Gunung Sinabung juga ditandai dengan gempa vulkanik. Pada umumnya gempa vulkanik terjadi dengan kekuatan kurang dari 5,5 ML .Ini termasuk gempa kecil, magnitudo kurang dari 5,5 ML, atau sumber seismik atipikal dengan radiasi energi seismik kecil, misalnya tremor, slow earthquakes. (Larmat, dkk., 2008) serta kedalamannya kurang dari 25 kilometer.
Gempa-gempa vulkanik tersebut diakibatkan oleh aliran fluida magma yang berpindah. Magma yang berpindah pada pipa utama kawah menimbulkan gempa-gempa vulkanik yang kekuatannya $<5,5 \mathrm{ML}$. Selain itu, magma juga mengintrusi lapisan kerak bumi dengan arah vertikal (dike) dan arah horizontal (sill) di sekitar Gunung Sinabung yang mengakibatkan gempa bumi pada kedalaman $<25 \mathrm{~km}$. Gempa vulkanik menghasilkan gelombang $\mathrm{P}$ dan gelombang $\mathrm{S}$ yang kecepatannya akan berubah jika menjalar di lapisan atau medium yang berbeda. Perubahan kecepatan dapat mengintepretasikan medium yang dilewati gelombang $\mathrm{P}$ dan gelombang $\mathrm{S}$. Nilai kecepatan pada setiap lapisan dapat diperoleh dari relokasi hiposenter dengan metoda JHD (Joint Hypocenter Determination).

\section{METODE PENELITIAN}

Badan Meteorologi Klimatologi dan Geofisika (BMKG) memasang seismograf dibeberapa lokasi di dekat Gunung Sinabung. Data yang tercatat tersebut akan disimpan di Earthquakes Repository BMKG. Penelitian ini menggunakan data gempa sebanyak 117 kejadian. Data yang diambil pada rentang waktu 1 Januari 2017 sampai 28 Februari 2017 dan pada koordinat $3,0931^{\circ} \mathrm{LU}-3,3543^{\circ} \mathrm{LU}$ dan $98,2928^{\circ}$ BT-98,6202 ${ }^{\circ}$ BT. Stasiun (sensor) yang merekam waktu tiba gelombang $\mathrm{P}$ dan gelombang $\mathrm{S}$ antara lain, TSI, KCSI, PSI, GSI, dan LASI. Data waktu tiba gelombang $\mathrm{P}$ lebih mudah terekam dibandingkan gelombang $\mathrm{S}$, sehingga tidak semua relokasi hiposenter gempa bumi menggunakan data waktu tiba gelombang $\mathrm{S}$ pada penelitian ini.

Metode yang digunakan untuk merelokasi hiposenter gempa vulkanik Gunung Sinabung pada penelitian ini adalah Joint Hypocenter Determination (JHD). Metode JHD termasuk dalam metode penentuan hiposenter dengan metode relatif sehingga dibutuhkan data awal. Waktu tiba pengamatan gelombang seismik dihasilkan dari fungsi nonlinear koordinat 
stasiun ( $\mathrm{x}$ '), parameter hiposenter ( $\mathrm{x}$, termasuk waktu kejadian dan koordinat geografi), dan kecepatan lintasan (v) sebagai data awal (Kissling, et al., 1994).

$$
t_{\text {obs }}=f(x, x, v) \ldots(1)
$$

Metode JHD dikembangkan oleh Douglas (1967) untuk menentukan parameter episenter dan koreksi stasiun menggunakan metode least-squares inversion. (Ratchkovsky, 1998). Dasar perhitungan dengan metode JHD adalah mencari selisih terkecil dari waktu tempuh pengamatan $\left(\mathrm{t}_{\mathrm{obs}}\right)$ dengan waktu tempuh perhitungan $\left(t_{\text {hit }}\right)$. Dengan menggunakan pendekatan ekspasi Deret Taylor pada persamaan (1), kita mendapatkan hubungan linier antara selisih waktu perjalanan dan hubungan terhadap parameter hiposenter $\left(\Delta x_{k i}\right)$ dan kecepatan $\left(\Delta v_{m}\right)$ :

$$
\begin{gathered}
t_{r e s}=t_{o b s}-t_{h i t}=\Delta t_{i j} \\
\Delta t_{i j}=\sum_{k=i}^{4} \frac{\partial t_{i j}}{\partial x_{k i}} \Delta x_{k i}+\sum_{\alpha=2}^{4} \frac{\partial t_{i j}}{\partial x_{\alpha j}^{\prime}} \Delta x_{\alpha j}^{\prime} \\
+\sum_{m=1}^{i} \frac{\partial t_{i j}}{\partial v_{m}} \Delta v_{m}
\end{gathered}
$$

Karena kesalahan stasiun dianggap nol $\left(\Delta x_{\alpha j}^{\prime}\right)$ maka persamaan di atas menjadi

$$
\Delta t_{i j}=\sum_{k=i}^{4} \frac{\partial t_{i j}}{\partial x_{k i}} \Delta x_{k i}+\sum_{m=1}^{i} \frac{\partial t_{i j}}{\partial v_{m}} \Delta v_{m} \ldots \text { (2) }
$$

Dimana : $\Delta t_{i j}=t_{i j}-t^{\circ}{ }_{i j}$

$$
\begin{aligned}
& \Delta x_{k i}=x_{k i}-x^{\circ}{ }_{k i} \\
& \Delta v_{m}=v_{m}-v^{\circ}{ }_{m}
\end{aligned}
$$

Dengan $\mathrm{t}$ : waktu jalar gelombang seismik $\mathrm{x}$ : koordinat geodetik hiposenter $\mathrm{v}$ : kecepatan gelombang seismik i : nomor gempa (q) $\mathrm{j}:$ nomor stasiun $(\mathrm{p})$

$\mathrm{m}$ : nomor kecepatan gelombang

seismik disetiap lapisan (l)

Solusi Matrik invers matrik r

$$
\begin{array}{lr}
c \times r & t= \\
\left(c^{T} \times c\right)^{-1} \times c^{T} \times t \ldots(3) & r=
\end{array}
$$

Dimana : $t=$ matrik data $\Delta t_{i j}$

$c$

$=$ matrik perkalian $\Delta x_{k i}$ dan $\Delta v_{m}$ $r=$ matrik model

Matrik $\mathrm{t}$ : data residu waktu jalar (t) datang ke stasiun (l) oleh gempa j (p x q)

Matrik c : data Kernel hiposenter dan kecepatan dengan ukuran (p x q $(4 q+1))$ Matrik $r$ : perbaikan model hiposenter dan kecepatan $(4 q+1)$

Pada umumnya selisih dari perhitungan ini, nilai Root Mean Square (RMS), akan menurun jika semakin banyak iterasi yang dilakukan. Namun perlu diketahui, jika proses iterasi dilakukan semakin banyak maka akan ada peningkatan nilai RMS. Nilai RMS akan semakin bertambah jika telah melewati titik minimun nilai RMS. Pada umumnya nilai RMS akan menurun (konvergen) jika data diiterasi sekitar lima sampai tujuh kali iterasi. (Ratchkovsky, 1998).

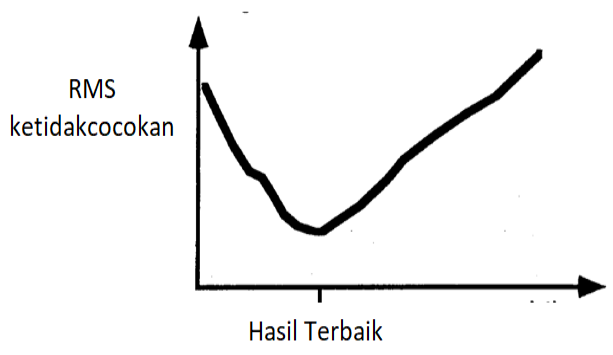

Gambar 1. Kualitas prakiraan dari penyelesaian perhitungan dengan iterasi. Hasil perrhitungan terbaik jika didapatkan nilai RMS terkecil. 
Software yang digunakan untuk merelokasi hiposenter pada penelitian ini adalah VELEST versi 3.3. VELEST dalam proses komputasinya menggunakan metode Joint Hypocenter Determination (JHD). (Kissling, et al., 1995). Software ini menggunakan empat input data. Pertama, letak stasiun (sensor) seismograf yang terdiri dari koordinat geografi dan elevasi tempat. Kedua, parameter hiposenter awal yang terdiri dari kedalaman, waktu kejadian, dan koordinat geografi. Ketiga, waktu jalar gelombang $\mathrm{P}$ dan gelombang $\mathrm{S}$ di setiap stasiun yang mencatat gelombang seismik. Keempat, model kecepatan global IASP91 yang digunakan sebagai model kecepatan referensi untuk mendapatkan kecepatan 1-D gelombang $\mathrm{P}$ dan gelombang $\mathrm{S}$ di Gunung Sinabung. Semua input data akan diubah ke dalam bentuk invers matrik dengan cara komputasi untuk mendapatkan nilai parameter hiposenter terbaik yang ditunjukan oleh nilai RMS terkecil. Output dari pengolahan ini adalah koreksi stasiun, parameter hiposenter akhir, waktu jalar gelombang seismik, dan kecepatan lokal gelombang $\mathrm{P}$ dan gelombang $\mathrm{S}$.

Tabel 1. Model kecepatan global IASP91 (Bormann, P.,

\begin{tabular}{|c|c|c|c|}
\hline $\begin{array}{c}\text { Kedalaman } \\
(\mathrm{km})\end{array}$ & $\begin{array}{c}\text { Jari-jari } \\
(\mathrm{km})\end{array}$ & $\begin{array}{c}\mathrm{V}_{\mathrm{p}} \\
(\mathrm{km} / \mathrm{s})\end{array}$ & $\mathrm{V}_{\mathrm{s}}(\mathrm{km} / \mathrm{s})$ \\
\hline 0 & 6371,00 & 5,8000 & 3,3600 \\
\hline 20,00 & 6351,00 & 5,8000 & 3,3600 \\
\hline 20,00 & 6351,00 & 6,5000 & 3,7500 \\
\hline 35,00 & 6336,00 & 6,5000 & 3,7500 \\
\hline 35,00 & 6336,00 & 8,0400 & 4,4700 \\
\hline 71,00 & 6300,00 & 8,0442 & 4,4827 \\
\hline 120,00 & 6251,00 & 8,0500 & 4,5000 \\
\hline 171,00 & 6200,00 & 8,1917 & 4,5102 \\
\hline 210,00 & 6161,00 & 8,3000 & 4.5180 \\
\hline 210,00 & 6161,00 & 8,3000 & 4,5220 \\
\hline
\end{tabular}

\begin{tabular}{|c|c|c|c|}
\hline $\begin{array}{c}\text { Kode } \\
\text { Stasiun }\end{array}$ & Latitude & Longitude & $\begin{array}{c}\text { Elevasi } \\
(\mathrm{m})\end{array}$ \\
\hline TSI & $3,5012^{\circ} \mathrm{LU}$ & $98,5645^{\circ} \mathrm{BT}$ & 81,81 \\
\hline KCSI & $\begin{array}{c}3,522185 \\
{ }^{\circ} \mathrm{LU}\end{array}$ & $\begin{array}{c}97,771575 \\
{ }^{\circ} \mathrm{BT}\end{array}$ & 198 \\
\hline PSI & $2,6952{ }^{\circ} \mathrm{LU}$ & $98,924{ }^{\circ} \mathrm{BT}$ & 1076,9 \\
\hline LASI & $\begin{array}{c}4,457251 \\
{ }^{\circ} \mathrm{LU}\end{array}$ & $\begin{array}{c}97,970367 \\
{ }^{\circ} \mathrm{BT}\end{array}$ & 13 \\
\hline GSI & $\begin{array}{c}1,3036^{\circ} \mathrm{LU} \\
97,5754{ }^{\circ} \mathrm{BT}\end{array}$ & 96 \\
\hline SNSI & $2,4089{ }^{\circ} \mathrm{LU}$ & $96,3267{ }^{\circ} \mathrm{BT}$ & 15 \\
\hline TRSI & $2,0256{ }^{\circ} \mathrm{LU}$ & $98,9594{ }^{\circ} \mathrm{BT}$ & 975,94 \\
\hline SBSI & $1,3988{ }^{\circ} \mathrm{LU}$ & $99,431{ }^{\circ} \mathrm{BT}$ & 300,57 \\
\hline MLSI & $\begin{array}{c}4,266851 \\
{ }^{\circ} \mathrm{LU}\end{array}$ & $\begin{array}{c}96,403984 \\
{ }^{\circ} \mathrm{BT}\end{array}$ & 75,82 \\
\hline LHMI & $\begin{array}{c}5,2286083 \\
{ }^{\circ} \mathrm{LU}\end{array}$ & $\begin{array}{c}96,9469333 \\
{ }^{\circ} \mathrm{BT}\end{array}$ & 32 \\
\hline
\end{tabular}

Tabel 2. Koordianat geografi dan elevasi letak stasiun (sensor)

Bagan Alur Kerja VELEST (Kissling, et al., 1995)

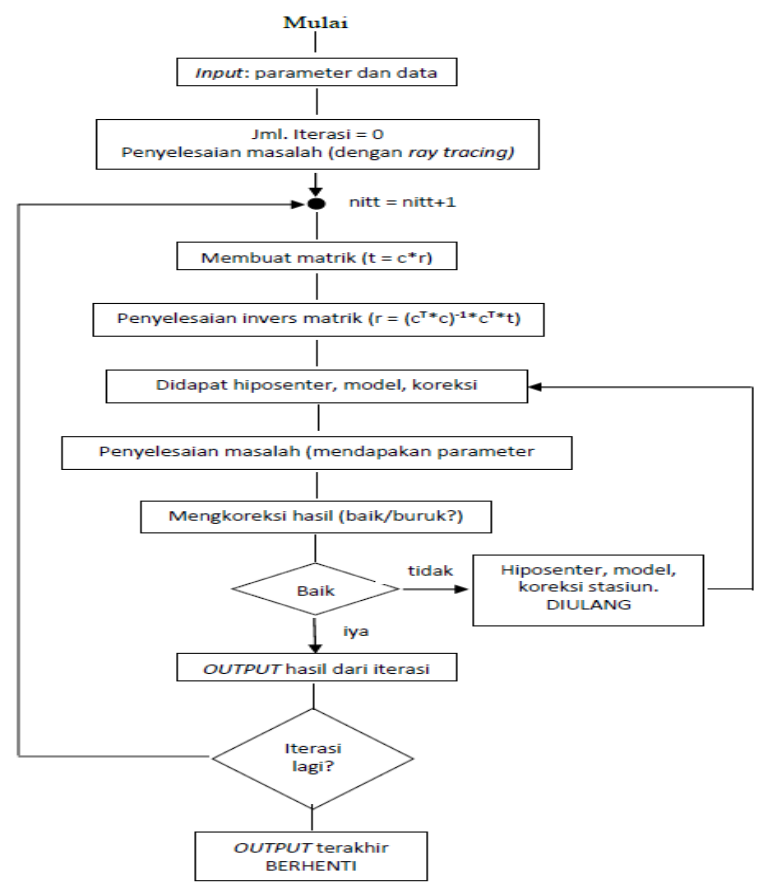




\section{HASIL DAN PEMBAHASAN}

Nilai RMS ketidakcocokan relokasi gempa vulkanik sebanyak 117 kejadian di Gunung Sinabung menggunakan software VELEST versi 3.3 dengan iterasi sebanyak tujuh kali. Banyaknya iterasi yang digunakan berdasarkan referensi yang didapat. RMS merupakan indikator yang menunjukan hasil iterasi tersebut baik atau tidak. Pada umumnya, nilai RMS yang dianggap baik adalah yang kurang dari dua. Nilai RMS dari 117 kejadian untuk setiap iterasi ditunjukan tabel berikut:

Tabel 3. Nilai RMS ketidakcocokan akan

menjadi lebih kecil dengan semakin bertambahnya iterasi.

\begin{tabular}{|c|c|}
\hline Iterasi ke- & RMS Ketidakcocokan \\
\hline 0 & 0.949402 \\
\hline 1 & 0.800165 \\
\hline 2 & 0.571225 \\
\hline 3 & 0.53526 \\
\hline 4 & 0.523216 \\
\hline 5 & 0.521295 \\
\hline 6 & 0.516448 \\
\hline 7 & 0.510472 \\
\hline
\end{tabular}

Adapun hasil iterasi untuk setiap kejadian gempa vulkanik ditunjukan tabel berikut:

Tabel 4. RMS untuk setiap kejadian dari 117 kejadian bernilai kuarang dari dua. Hal ini menunjukan bahwa relokasi yang dilakukan sudah baik.

\begin{tabular}{|c|c|c|c|c|c|c|c|}
\hline Gempa & RMS & Gempa & RMS & Gempa & RMS & Gempa & RMS \\
\hline 1 & 0,53 & 31 & 0,61 & 61 & 0,06 & 91 & 0,67 \\
\hline 2 & 0,87 & 32 & 0,50 & 62 & 0,76 & 92 & 0,30 \\
\hline 3 & 0,27 & 33 & 0,48 & 63 & 0,45 & 93 & 0,39 \\
\hline 4 & 0,41 & 34 & 0,48 & 64 & 0,16 & 94 & 0,06 \\
\hline 5 & 0,32 & 35 & 0,98 & 65 & 0,45 & 95 & 0,50 \\
\hline 6 & 0,58 & 36 & 0,56 & 66 & 0,19 & 96 & 0,39 \\
\hline 7 & 0,09 & 37 & 0,41 & 67 & 0,50 & 97 & 0,99 \\
\hline 8 & 0,01 & 38 & 0,36 & 68 & 0,68 & 98 & 0,13 \\
\hline 9 & 0,02 & 39 & 0,35 & 69 & 0,57 & 99 & 0,50 \\
\hline 10 & 0,76 & 40 & 0,34 & 70 & 0,56 & 100 & 0,07 \\
\hline 11 & 0,26 & 41 & 0,74 & 71 & 0,49 & 101 & 0,37 \\
\hline 12 & 0,85 & 42 & 0,36 & 72 & 0,46 & 102 & 1,03 \\
\hline 13 & 0,47 & 43 & 0,55 & 73 & 0,51 & 103 & 0,38 \\
\hline 14 & 0,25 & 44 & 0,35 & 74 & 0,50 & 104 & 0,40 \\
\hline 15 & 0,21 & 45 & 0,30 & 75 & 0,57 & 105 & 0,03 \\
\hline 16 & 0,15 & 46 & 0,09 & 76 & 0,77 & 106 & 0,01 \\
\hline 17 & 1,27 & 47 & 0,34 & 77 & 1,31 & 107 & 0,13 \\
\hline 18 & 0,53 & 48 & 0,10 & 78 & 0,03 & 108 & 0,02 \\
\hline 19 & 1,15 & 49 & 0,32 & 79 & 0,13 & 109 & 0,07 \\
\hline 20 & 0,15 & 50 & 0,88 & 80 & 0,00 & 110 & 0,05 \\
\hline 21 & 0,60 & 51 & 1,60 & 81 & 0,29 & 111 & 0,35 \\
\hline 22 & 0,60 & 52 & 0,46 & 82 & 0,40 & 112 & 1,06 \\
\hline 23 & 0,46 & 53 & 0,48 & 83 & 0,50 & 113 & 0,79 \\
\hline 24 & 0,41 & 54 & 0,26 & 84 & 0,57 & 114 & 0,38 \\
\hline 25 & 0,54 & 55 & 0,39 & 85 & 0,65 & 115 & 0,20 \\
\hline 26 & 0,63 & 56 & 0,41 & 86 & 0,09 & 116 & 1,10 \\
\hline 27 & 0,28 & 57 & 0,38 & 87 & 0,04 & 117 & 0,46 \\
\hline 28 & 1,50 & 58 & 0,80 & 88 & 0,12 & & \\
\hline 29 & 0,27 & 59 & 0,08 & 89 & 0,38 & & \\
\hline 30 & 0,26 & 60 & 0,15 & 90 & 0,48 & & \\
\hline
\end{tabular}


Hasil relokasi hiposenter gempa bumi di wilayah Gunung Sinabung dapat di petakan ke dalam bentuk dua dimensi dan tiga dimensi. Pada peta dua dimensi tersebut dapat memperlihatkan persebaran gempa di wilayah Gunung Sinabung. Sedangkan peta tiga dimensi menunjukan hiposenter gempa bumi. Seismisitas gunung berapi dihasilkan dari perubahan tingkat regangan yang disebabkan oleh banyak proses geologis, hidrotermal dan magmatik yang terjadi karena volume cairan magmatik tiga fase yang besar bermigrasi dari kerak bawah ke permukaan (McCausland, W., dkk., 2017).

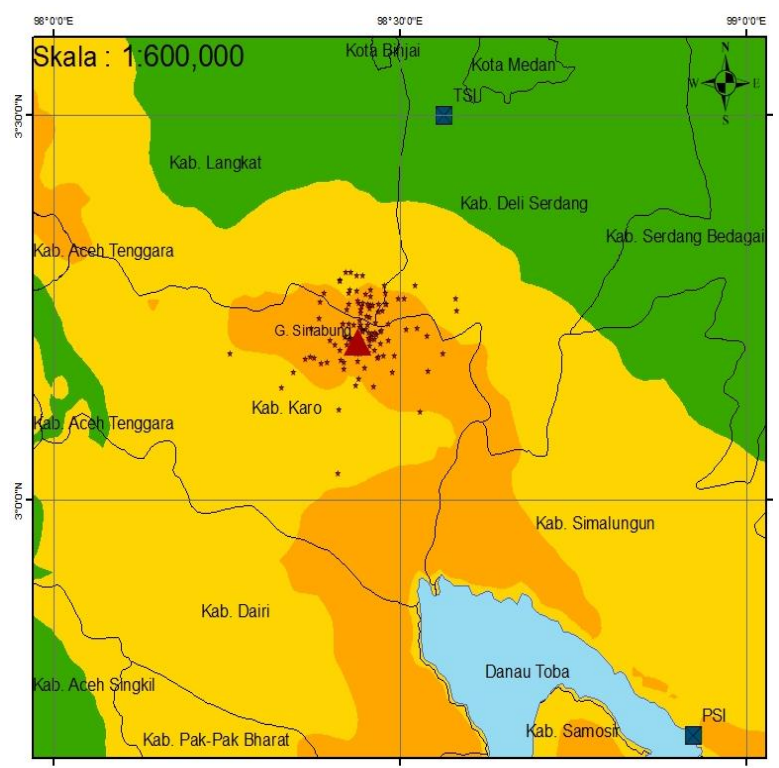

Gambar 2. Dari gambar tersebut menunjukan bahwa persebaran episenter dominan ke arah utara.

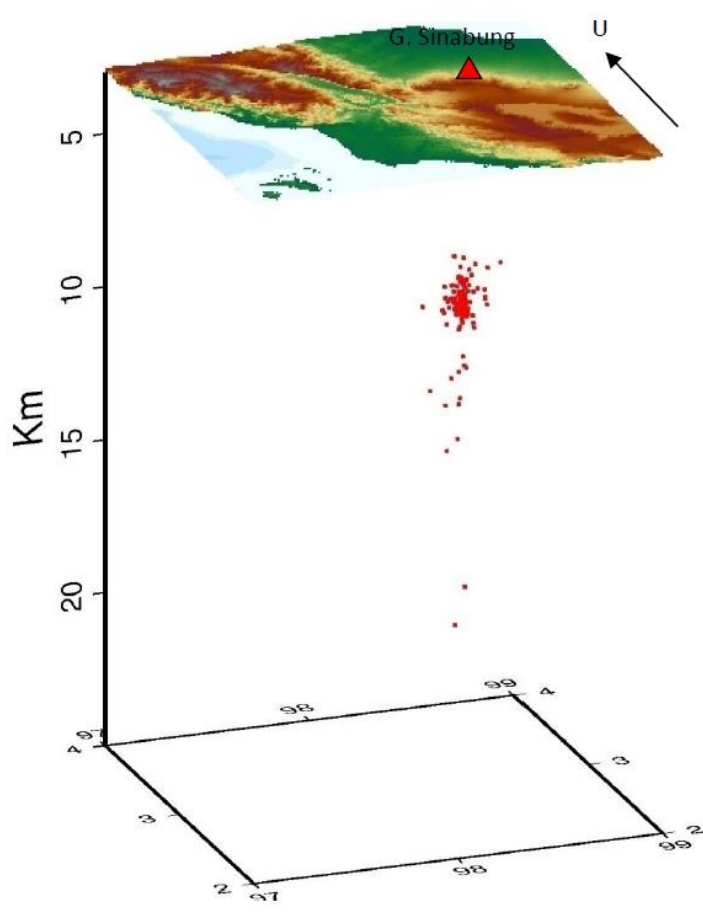

Gambar 3. Dari gambar tersebut menunjukan bahwa hiposenter dominan pada kedalaman $8 \mathrm{~km}$ sampai $10 \mathrm{~km}$.

Output model kecepatan dari relokasi hiposenter gempa bumi di wilayah Gunung Sinabung menunjukan perbedaan nilai dengan model kecepatan global IASP91. Perbedaan nilai tersebut menunjukan kondisi bawah permukaan di wilayah Gunung Sinabung. Nilai model kecepatan global IASP91 gelombang $\mathrm{P}$ dan gelombang $\mathrm{S}$ dan model kecepatan gelombang $\mathrm{P}$ dan gelombang $\mathrm{S}$ ditunjukan tabel berikut ini: 
Tabel 5. Hasil dari relokasi hiposenter memberikan model kecepatan 1-D gelombang $\mathrm{P}$ dan gelombang $S$ di wilayah Gunung

\begin{tabular}{|c|c|c|c|c|}
\hline $\begin{array}{c}\text { Kedala } \\
\mathbf{m a n} \\
(\mathbf{k m})\end{array}$ & $\begin{array}{c}\mathbf{V p} \\
\mathbf{( k m} / \mathbf{s}) \\
\mathbf{I A S P 9} \\
\mathbf{1}\end{array}$ & $\begin{array}{c}\mathbf{V p} \\
\mathbf{( k m} / \mathbf{s}) \\
\mathbf{G . S i n a} \\
\mathbf{b u n g}\end{array}$ & $\begin{array}{c}\mathbf{V s} \\
\mathbf{( k m} / \mathbf{s}) \\
\mathbf{I A S P 9} \\
\mathbf{1}\end{array}$ & $\begin{array}{c}\mathbf{V s} \\
\mathbf{( k m} / \mathbf{s}) \\
\mathbf{G . S i n a} \\
\mathbf{b u n g}\end{array}$ \\
\hline 0,0 & 5,8000 & 5.9200 & 3,3600 & 2,9100 \\
\hline 20,00 & 5,8000 & 6.0300 & 3,3600 & 3,4600 \\
\hline 20,01 & 6,5000 & 6.5900 & 3,7500 & 3,4600 \\
\hline 35,00 & 6,5000 & 6.6400 & 3,7500 & 3,7500 \\
\hline 35,01 & 8,0400 & 7.7100 & 4,4700 & 4,4700 \\
\hline 71,00 & 8,0440 & 8.0400 & 4,4820 & 4,4800 \\
\hline 120,00 & 8,0500 & 8.0500 & 4,5000 & 4,5000 \\
\hline 120,01 & 8,0500 & 8.0500 & 4,5000 & 4,5000 \\
\hline \multicolumn{5}{|c|}{ Sinabung } \\
\end{tabular}

Ada perbedaan nilai kecepatan gelombang $\mathrm{P}$ dan gelombang $\mathrm{S}$ dari model kecepatan global IASP91 dengan model kecepatan lokal Gunung Sinabung. Untuk memudahkan melihat perbadaannya, penulis telah membuat plot kedua model kecepatan tersebut berdasarkan jenis gelombangnya.

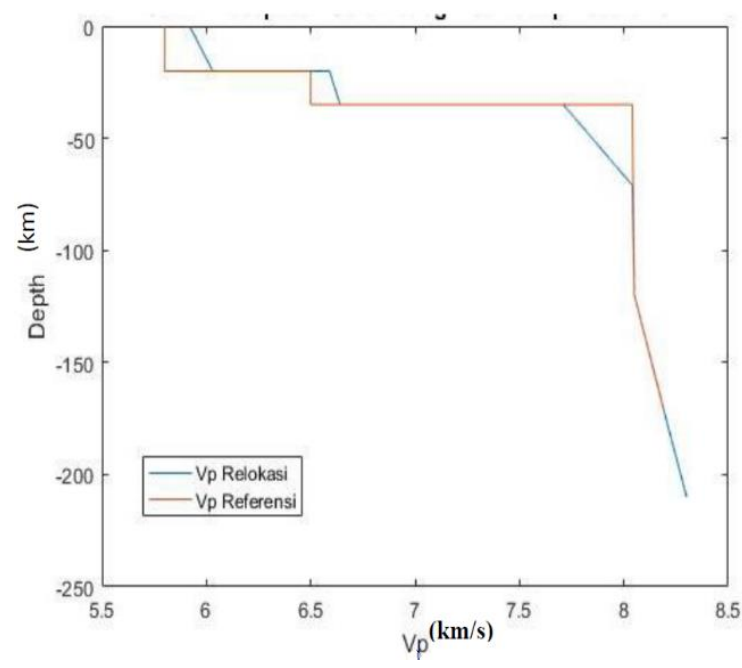

Gambar 4. Nilai model kecepatan gelombang P di Gunung Sinabung dibandingkan dengan model kecepatan referensi (IASP91).

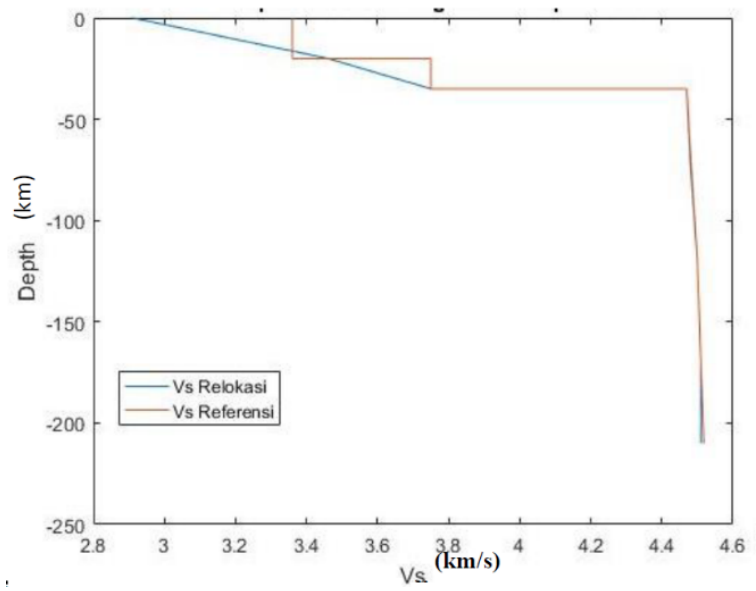

Gambar 5. Nilai model kecepatan gelombang $S$ di Gunung Sinabung dibandingkan dengan model kecepatan referensi (IASP91).

Model kecepatan gelombang P bernilai lebih besar dari model kecepatan global IASP91 pada kedalaman 0 sampai $20 \mathrm{~km}$. Kecepatan gelombang seismik akan merambat lebih cepat di medium yang memiliki densitas yang lebih besar. Korelasi antara kecepatan gelombang kompresi (gelombang P) dan densitas sangat penting karena memungkinkan perkiraan densitas kerak yang dibuat untuk pemodelan gravitasi dari kecepatan pembiasan seismik dan sebaliknya, kerapatan batuan dapat digunakan untuk memprediksi kecepatan seismik. (Christensen, N. I., 1995). Pada kedalam 35 $\mathrm{km}$ sampai $71 \mathrm{~km}$ kecepatan gelombang $\mathrm{P}$ lebih kecil dibandingkan dengan model keceptan referensi. Hal itu diakibatkan lapisan tersebut masih terdapat unsur kimia kerak bagian atas seperti silika. Lapisan kerak lebih tebal dibandingkan model global karena terdapat akar gunung.

Pada kecepatan gelombang $\mathrm{S}$ di wilayah Gunung Sinabung memiliki kecepatan yang lebih kecil dibandingkan model kecepatan IASP91 pada kedalaman $0 \quad \mathrm{~km} \quad$ (di permukaaan). Nilai kecepatan gelombang $S$ memiliki kecenderungan meningkat, sebanding dengan bertambah kedalaman lapisan. Berbeda dengan gelombang $\mathrm{P}$, penjalaran gelombang $S$ dipengarui oleh wujud medium yang dilalui. Hal itu disebabkan gelombang $\mathrm{S}$ termasuk gelombang tranversal. Sifat magma yang tidak padat, kental, menyebabkan nilai kecepatan gelombang $\mathrm{S}$ menurun. 
Gambar 6. Kecepatan gelombang kompresif (gelombang P) rata-rata untuk jenis batuan utama. (Christensen, N. I., 1995).

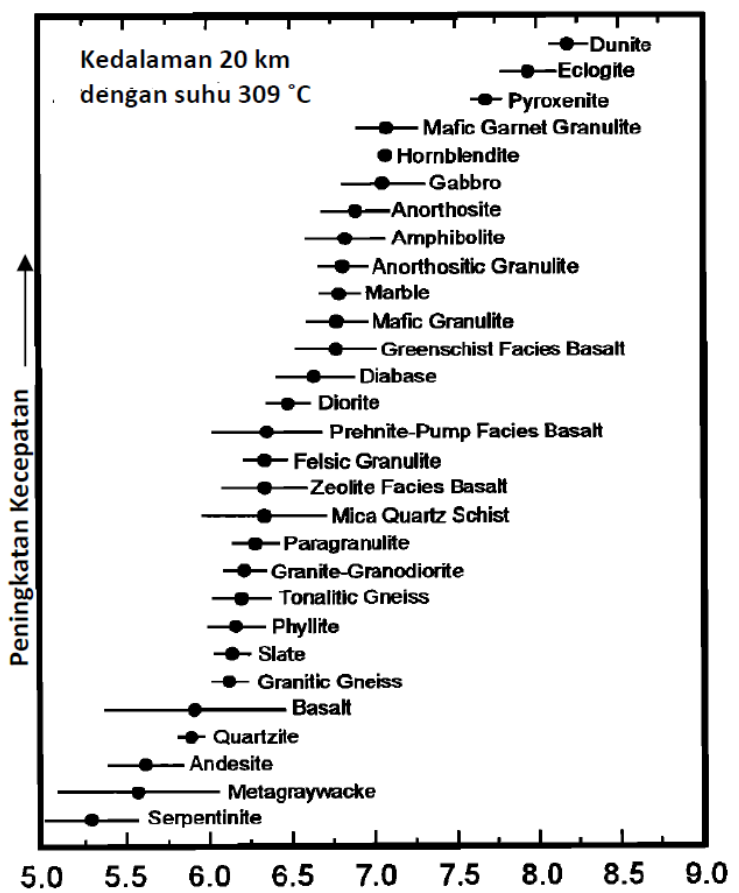

Kecepatan gelombang kompresif atau gelombang $\mathrm{P}(\mathrm{km} / \mathrm{s})$

Setelah dicocokan dengan tabel referensi menurut Nikolas I. Christensen tersebut, diketahui bahwa jenis batuan pada kedalam $20 \mathrm{~km}$ di Gunung Sinabung adalah batuan diorite. Diorite termasuk kedalam jenis batuan beku. Hal itu menyebabkan diorite memiliki densitas yang lebih tinggi dibandingkan dengan batuan berada di lapisan kerak lainnya. Diorite terbentuk dari magma Gunung Sinabung yang membeku di dalam lapisan bawah permukaan.

\section{KESIMPULAN}

Distribusi hiposenter dominan terletak pada kedalaman $8 \mathrm{~km}$ sampai $10 \mathrm{~km}$ di bawah permukaan di dekat kawah Gunung Sinabung. Hal itu menunjukan bahwa gempa yang terekam seismograf bersumber dari aktivitas vulkanik di Gunung Sinabung. Persebaran episenter Gunung Sinabung terlihat dominan ke arah utara. Kemungkinan aliran magma sedang bermigrasi ke utara, namun hal itu masih perlu dilakukan pengkajian yang lebih lanjut.
Model kecepatan 1-D gelombang $\mathrm{P}$ dan gelombang $\mathrm{S}$ di wilayah Gunung Sinabung memiliki karakteristik model penjalaran di daerah gunung api. Beberapa penelitian sebelumnya menyebutkan bahwa efek kesalahan model kecepatan dapat diminimalisir secara efektif dengan menggunakan model relokasi relatif hiposenter (Poupinet. et al., 1984, Got et al., 1994 dalam Sahara, dkk., 2009). Model kecepatan tersebut dapat digunakan sebagai data pemetaan bawah permukaan. Data kecepatan 1-D gelombang $\mathrm{P}$ dan gelombang $\mathrm{S}$ digunakan sebagai data input pemodelan tomografi. Dengan model tomografi dapat diketahui lebih jelas kondisi bawah permukaan di Gunung Sinabung.

Jenis batuan bawah permukaan dapat diketahui dengan membandingkan data lapangan dengan data percobaan di laboratorium. Setiap jenis batuan memiliki densitas yang berbeda. Densitas batuan mempengaruhi nilai kecepatan perambatan gelombang kompresif (gelombang P). Selain densitas lapisan ,wujud lapisan bawah permukaan mempengaruhi nilai kecepatan perambatan gelombang transversal (gelombang S). Hal itu diakibatkan karena gelombang $\mathrm{S}$ menjalar dengan menggetarkan partikel medium yang arahnya tegak lurus dengan rambatan gelombang tersebut. Sehingga wujud benda dapat mempengaruhi nilai kecepatan gelombang S. Semua informasi tersebut dapat dijadikan salah satu data untuk mengintepretasi lapisan bawah permukaan.

\section{Ucapan terima kasih}

Puji syukur penulis panjatkan kepada Allah Yang Maha Kuasa, karena dengan rahmat dan karunia-Nya, penulisan dapat menyeselaikan pembuatan full paper ini. Penulis mengucapkan terimakasih kepada Bapak Rasmid yang telah memberikan materi tentang pengolahan data relokasi gempa bumi dan memberikan data untuk direlokasi, serta kepada Bapak Hendri Subakti yang berkenan menjadi dosen pembimbing serta me-review karya ilmiah ini. Terakhir pnulis ucapkan terimakasih kepada rekan Yoga Dharma Persada yang 
membantu dalam pembuatan full paper ini serta semua pihak yang mendorong penulis untuk semangat dalam berkarya.

\section{DAFTAR PUSTAKA}

Anonim, 2017, Gunung Sinabung Erupsi Sampai Tujuh Kali, http://www.dw.com/id/gunung-sinabungerupsi-sampai-tujuh-kali/a-37425366.

Bormann, P. 2002. Global 1-D Earth models. GeoForschungsZentrum Potsdam, Telegrafenberg, D-14473 Potsdam, Germany E-mail: pb65@gmx.net

Christensen, N. I. and Mooney, W. D., 1995, Seismic velocity structure and composition of the continental crust: A global view, Journal of Geophysical Research, American Geophysical Union.

Islahudin. 2013. Ini Riwayat Erupsi dan Letusan Gunung

Sinabung, (https://www.merdeka.com/peristiwa/iniriwayat-erupsi-dan-letusan-gunungsinabung.html).

Kissling, E. 1994. Initial reference models in local earthquake tomography, Journal of
Geophysical Research, American Geophysical Union,

Kissling, E., Kradolfer U., dan Maurer H. 1995. Velest User's Guide, Institute of Geophysic, ETH Zuerich.

Larmat, C., Johnson P. A., dan Huang L. 2008. 2004 M6.0 Parkfield earthquake characterization using Time Reversal, The Journal of Acoustical Society of America, AIP Publishing.

Ratchkovsky, N. A., Pujol, J., dan Biswas, N. N. 1998. Relocation of Shallow Earthquakes in Southern Alaska using Joint Hypocenter Determination Method, Journal of Seismology, Kluwer Academic Publisher, Belgium.

Sahara, D. P. 2009. Aplikasi Metode Double Difference untuk Relokasi Hiposenter Gempa Vulkanik Gunung Kelud secara Akurat. JTM, Vol. XVI No. 1, Bandung.

McCausland, W. 2017. Using a process-based model of pre-eruptive seismic patterns to forecast evolving eruptive styles at Sinabung Volcano, Journal of Volcanology and Geotermal Research, Volgeo, doi: 
